\title{
BASES EPISTEMOLÓGICAS DO POSITIVISMO E DO MATERIALISMO DIALÉTICO: NOTAS PARA REFLEXÃO
}

\author{
Simone Medeiros \\ simone.medeiros3@gmail.com
}

\begin{abstract}
RESUMO: O texto a seguir tem por objetivo central compreender os fundamentos epistemológicos que sustentam a teoria positivista (Augusto Comte) e o materialismo dialético (Karl Marx), a partir da emergência do pensamento moderno. Para explicar adequadamente a natureza e o caráter desses enfoques clássicos do conhecimento no mundo ocidental, consideramos conveniente contextualizar historicamente cada um deles. Retomamos tendências, filósofos e movimentos (racionalismo, empirismo, criticismo e o idealismo objetivista) com a intenção de alcançar o objetivo postulado, portanto, compreender as bases epistemológicas que sustentam a teoria positivista e o materialismo dialético.
\end{abstract}

PALAVRAS-CHAVE: Teoria do conhecimento; materialismo histórico-dialético; positivismo.

Entre os séculos XIV e XVI, generalizou-se na Europa uma série de movimentos artísticos e científicos que tinham em comum o rompimento com valores postos pela Idade Média e a recuperação de outros valores inspirados na Grécia e na Roma antigas. Esses movimentos receberam o nome de Renascimento, caracterizado como uma tendência cultural laica, racional e científica. O elemento central do Renascimento foi o humanismo, no sentido da valorização do ser humano, criação privilegiada por Deus. Daí surge o antropocentrismo renascentista, ou seja, a ideia de que o homem se encontra no centro do universo, opondo-se ao teocentrismo medieval, que tinha Deus como o centro de todas as coisas e entendia o homem como inferior, corrompido pelo pecado.

No período renascentista, valorizava-se o homem como ser racional, dotado de um dom quase divino - a razão -, e, por isso mesmo, capaz de interpretar e conhecer a natureza. A aproximação do homem com Deus se fazia por meio da criatividade e da genialidade, atributos que lhe davam a imagem e a semelhança do Criador, possibilitando ao homem emergir das trevas da sujeição escolástica. 
Em meio a essa efervescência, que se caracteriza pela centralidade política absolutista, reforma protestante e renascimento artístico e cultural e, sobretudo, pela ruptura com o imobilismo feudal, assiste-se, na Europa, ao surgimento do capitalismo comercial que se sustenta no fortalecimento cada vez maior da burguesia, passando a ter papel decisivo na definição dos rumos políticos, econômicos, religiosos e culturais (HOBSBAWN: 2009). Esse cenário constitui-se em uma nova realidade, portanto, um novo objeto a ser conhecido. Algumas questões postuladas na época aprofundam problemas anteriores e fundamentam reflexões e debates; dentre elas, destacam-se: de qual sujeito estamos falando? De um sujeito emergido em dúvidas e incertezas? Em busca de novos parâmetros para conhecer? O que implica conhecer nesta nova realidade? O homem pode conhecer?

Esse período de profundas transformações na visão de mundo do homem ocidental traz consigo a rejeição das ideias até então dominantes e que estiveram garantidas, sobretudo, pela força de autoridades agora contestadas.

E, para superar incertezas e dúvidas desse momento histórico, no campo filosófico e no científico, era preciso tomar um caminho diferente das bases do sistema feudal, de forma que conduzisse, com segurança, a certezas científicas universais, era preciso criar um método científico. E essa preocupação se generaliza a partir do século XVI e vai caracterizar a investigação filosófica dos séculos subsequentes.

Consciência e realidade, homem e mundo são, assim, separados em duas instâncias distintas, o interno e o externo, transformando a teoria do conhecimento em uma doutrina filosófica que investiga as possibilidades da relação entre o sujeito e o objeto.

Nessa perspectiva, todas as respostas acerca das possibilidades do conhecimento se polarizam por meio de dois grupos: os idealistas filosóficos, que consideram primário o espírito, a ideia, o pensamento, a consciência; e os materialistas filosóficos, que consideram que a matéria vem primeiro, que ela existiu antes do pensamento. A ideia de consciência seria um aspecto secundário.

E é a partir dessa polarização entre as relações sujeito (que conhece) e objeto (que é conhecido) que se postulam os desafios da reflexão do conhecimento no mundo moderno, ou seja: é possível conhecer o mundo? Pode o sujeito captar o objeto em toda sua dimensão, a coisa em si? É capaz o homem de desvendar as leis que regem o universo? Nossa consciência tem a capacidade de refletir de maneira adequada a realidade objetiva?

\section{RACIONALISMO, CRITICISMO E IDEALISMO OBJETIVISTA}


$\mathrm{Na}$ idade média, o pensamento filosófico era dominado pela religião, em grande medida, por duas correntes teológicas: de um lado a teologia de Santo Agostinho (354-430), que defendia que a salvação jamais seria obtida pelo homem, pecador, mas somente graças à intervenção divina, na medida em que Deus incluía o perdão entre os seus infinitos atributos; e do outro, a filosofia escolástica, com origem no pensamento de Santo Tomás de Aquino (1225-1274), que desenvolveu a tese de que o progresso humano não dependia apenas da vontade divina, mas também do esforço do homem. Assim, o homem surgiria como um ser privilegiado, uma vez que, dotado de razão, estava preparado para assumir o seu destino. Buscava-se, dessa forma, conciliar fé e razão, refutando a ideia agostiniana de predestinação.

$\mathrm{Na}$ idade moderna, duas grandes orientações metodológicas surgem: de um lado, a perspectiva empirista proposta por Francis Bacon (1561-1626), a preconizar uma ciência sustentada pela observação e pela experimentação e que formulava indutivamente as suas leis, partindo da consideração dos casos ou eventos particulares para chegar a generalizações; por outro lado, inaugurando o racionalismo moderno, Descartes (1596-1650) busca na razão - que as matemáticas encarnavam de maneira exemplar - os recursos para a recuperação da certeza científica (HOBSBAWN: 2009).

Descartes (1999), nos séculos XV e XVI, assumindo o espírito iluminista de sua época, que acabara de nascer, e centralizando a capacidade racional humana na busca do conhecimento, lança as bases do racionalismo como única fonte do conhecimento. Acreditava na existência da verdade absoluta, incontestável. E, para atingi-la, desenvolveu o método da dúvida, que consistia em questionar todas as teorias ou ideias pré-existentes. Adota como princípio o 'próprio eu' como campo de batalha entre a certeza e a incerteza. Com o tempo, convenceu-se de que a única verdade possível era sua capacidade de duvidar, reflexo da capacidade de pensar. Assim, a verdade absoluta estaria sintetizada na fórmula 'eu penso', com base na qual concluiu sua própria existência. Sua teoria passou a ser resumida na frase 'penso, logo existo'.

[...] percebi que, ao mesmo tempo que eu queria pensar que tudo era falso, fazia-se necessário que eu, que pensava, fosse alguma coisa. E, ao notar que esta verdade: eu penso, logo existo, era tão sólida e tão correta que as mais extravagantes suposições dos céticos não seriam capazes de lhe causar abalo, julguei que podia considerá-la, sem escrúpulo algum, o primeiro princípio da filosofia que eu procurava [...] compreendi, então, que eu era uma substância cuja essência ou natureza consiste apenas no pensar, e que, para ser, não necessitava de lugar algum, nem depende de qualquer coisa material. (DESCARTES: 1999, p. 62)

Se da incerteza desdobra-se uma primeira certeza - "Se duvido, penso" -, essa é uma certeza a respeito da própria subjetividade. Nada fica, portanto, garantido a respeito da 
realidade exterior. Todavia, basta uma primeira certeza plena para que a 'ordem natural' possibilite conhecer o desconhecido: "Se duvido, penso" e se "Penso, logo existo".

[...] meu ser não era totalmente perfeito, pois via claramente que o conhecer é perfeição maior do que o duvidar, decidi procurar de onde aprendera a pensar em algo mais perfeito do que eu era; e descobri, com evidência, que devia ser de alguma natureza que fosse realmente perfeita [...] restava somente que tivesse colocado em mim por uma natureza que fosse de fato perfeita do que a minha, e que possuísse todas as perfeições de que eu poderia ter alguma ideia, ou seja, para dizê-lo numa única palavra, que fosse Deus. (DESCARTES: 1999, p. 63 e 64)

Descartes (1999) acreditava na existência de um Deus criador do universo, para ele um mecanismo extremamente sofisticado e governado por leis eternas. Caberia ao homem, dotado da razão, desvendar tais leis. Para ele não havia interferência divina no universo após sua criação.

[...] tendo Deus concedido a cada um de nós alguma luz para diferenciar o verdadeiro do falso, não julgaria dever satisfazer-me um único instante com as opiniões dos outros, se não tencionasse utilizar o meu próprio juízo em analisá-las, quando fosse tempo. (DESCARTES: 1999, p. 57)

O Deus cartesiano é, assim, a garantia da objetividade do conhecimento científico. Descartes, primeiro, demonstra que a existência do mundo exterior é possível. Em seguida, que é mais que possível, é provável. Finalmente, que é mais que provável, é certa. Deus é a garantia da objetividade.

No entanto, a centralidade da teoria de Descartes é a introdução da temática do sujeito que conhece como fundamento do seu método. Esse sujeito pode assegurar um conhecimento verdadeiro e seguro do objeto. Ele parte, portanto, da premissa de que, antes de voltar-se para o objeto, esse sujeito precisa voltar-se para si mesmo e fundamentar nele possibilidades do conhecimento.

Essa perspectiva ontológica de Descartes é questionada e superada por Kant (17241804). Mas, é importante destacar que Kant fala do final do século XVIII e início do século XIX, período marcado por grandes revoluções (1789-1848) e pelo triunfo, segundo Hobsbawn (2009), da indústria capitalista, da classe média ou da sociedade burguesa liberal e das economias e Estados do mundo, cujo centro era os Estados rivais vizinhos da Grã-Bretanha e França. E, sobretudo, da filosofia iluminista da época:

De fato, o 'iluminismo', a convicção no progresso humano, na racionalidade, na riqueza e no controle sobre a natureza - de que estava profundamente imbuído o 
século XVIII - derivou sua força primordialmente do evidente progresso da produção, do comércio e da racionalidade econômica e científica que se acreditava estar associada a ambos. (HOBSBAWN: 2009, p. 41)

Esse período, caracterizado ainda, conforme Hobsbawn (2009), por um individualismo secular, racionalista e progressista, dominava o pensamento 'esclarecido'.

Libertar o indivíduo das algemas que o aguilhoavam era o seu principal objetivo: do tradicionalismo ignorante da Idade Média, que ainda lançava sua sombra pelo mundo, da superstição das igrejas (distintas da religião 'racional' ou 'natural'), da irracionalidade que dividia os homens em hierarquia de patentes mais baixas e mais altas de acordo com o nascimento ou algum outro critério irrelevante. A liberdade, a igualdade e, em seguida, a fraternidade de todos os homens eram seus slogans. No devido tempo se tronaram slogans da Revolução Francesa. (HOBSBAWN: 2009, p. 42)

Nesse contexto e a partir de questões como: que posso saber? que hei de fazer? que posso esperar?, Kant, na tentativa de determinar as leis e os limites do pensamento, busca sintetizar, mas, sobretudo, superar - numa perspectiva crítica da razão pura ${ }^{1}$ - o racionalismo de René Descartes (raciocínio dedutivo) e o empirismo inglês de David Hume (que valoriza a indução).

Em Crítica da Razão Pura, Kant (2002) parte da compreensão de que 'Dúvida não há que todo o nosso conhecimento principia pela experiência'. Porém, mais adiante, afirma: 'se todo o conhecimento se principia com a experiência, isso não prova que todo ele derive da experiência'. E como provocação ao debate, postula:

[...] se poderá haver um conhecimento tal, independente da experiência e de todas as impressões dos sentidos. Denomina-se a priori esse conhecimento e distingue-se do empírico, cuja origem é posteriori, ou seja, na experiência. (KANT: 2002, p. 44)

São puros, para Kant, os conhecimentos; a priori aqueles que não têm mistura nenhuma de empírico. Afirma:

[...] dever-se-á, na divisão desta ciência, ter em vista que nela não entra conceito algum que contenha algo de empírico, quer dizer, o conhecimento a priori deve ser totalmente puro. (KANT: 2002, p. 60)

Para Kant (2002), a crítica da razão pura possibilita e leva à ciência, ao passo que o uso dogmático da razão, sem crítica, conduz, pelo contrário, a afirmações sem bases sólidas, a que se podem contrariar a verdade e, sem dúvida, ao ceticismo.

Denomina transcendental todo o conhecimento que em geral se ocupa menos dos objetos, que do nosso modo de conhecê-los, na medida em que este deve ser possível, $a$ 
priori. Portanto, o pensamento de Kant (2002) consiste na inversão copernicana, ou seja, não é o objeto que determina o sujeito, mas o sujeito que determina o objeto. O objeto só se torna conhecido na medida em que o sujeito determina o objeto. As categorias são conceitos, todavia, puros, a priori, anteriores à experiência e que, por isso, tornam-na possível. Portanto, ultrapassando os limites da experiência, aplica arbitrariamente as categorias e pretende conhecer o incognoscível.

Para Kant (2002), "o conhecimento não é reflexo do objeto exterior: é o próprio espírito que constrói o objeto de seu saber". Não é possível conhecer o real em verdade, apenas sua aparência, os ditos fenômenos, algo que aparece para a consciência. Ele desenvolveu a noção de um argumento transcendental para mostrar que, apesar de não podermos saber necessariamente verdades sobre o mundo como ele é em si, estamos forçados a perceber e a pensar acerca do mundo de certas formas: podemos saber com certeza um grande número de coisas sobre o mundo como ele nos aparece.

Só a crítica pode cortar pela raiz o materialismo, o fatalismo, o ateísmo, a incredulidade dos espíritos fortes, o fanatismo e a superstição, que se podem tornar nocivos a todos e, por último, também o idealismo e ceticismo, que são acima de tudo perigosos para as escolas e dificilmente se propagam ao público. (KANT: 2002, p. 38)

A filosofia Kantiana postula três grandes problemas: a concepção de idealismo como idealismo transcendental; a oposição entre razão teórica e razão prática; e o problema da coisa em si. Muitos filósofos tentaram desenvolver essas teses na perspectiva da razão prática, tanto no idealismo subjetivo, como no idealismo objetivo. Mas a tentativa de superação do kantismo não se consegue até a formulação do pensamento de Hegel (KANT: 2002).

No final do século XVIII e início do século XIX, entre 1789 e 1848, a Europa e a América foram, segundo Hobsbawn (HOBSBAWN: 2009, p. 57), inundadas por especialistas, máquinas a vapor, maquinaria para processamento e transformação do algodão e investimentos britânicos. Para esse autor, se - neste período - a economia do mundo foi caracterizada pela Revolução Industrial, sua política e ideologia foram formadas fundamentalmente pela Revolução Francesa.

O final do século XVIII foi uma época de crise para os velhos regimes da Europa e seus sistemas econômicos, e suas últimas décadas foram cheias de agitações políticas, às vezes, atingindo o ponto da revolta e de movimentos coloniais em busca de autonomia. 
antiburguesa eram os jacobinos, cujo nome veio significar 'revolução radical' em toda parte. (HOBSBAWN: 2009, p. 95)

Para esse autor, essa não foi uma fase cômoda para se viver, pois a maioria dos homens sentia fome e muitos tinham medo, mas foi um fenômeno tão terrível e irreversível quanto a primeira explosão nuclear, e toda a história tem sido permanentemente transformada por ela. A maior expressão-síntese dessa época e que define o momento em que o mundo vive é a figura do francês Napoleão Bonaparte.

[...] com a sua chegada, como que por milagre, os insolúveis problemas do Diretório se tornaram solúveis. Em poucos anos a França tinha um Código Civil, uma concordata com a Igreja e até mesmo o mais significativo símbolo da estabilidade burguesa - um Banco Nacional. E o mundo tinha o seu primeiro mito secular. (HOBSBAWN: 2009, p. 111)

Napoleão Bonaparte foi a figura com que todo homem que partisse os laços com a tradição podia se identificar em seus sonhos (HOBSBAWN: 2009).

É nesse contexto, de consolidação do capitalismo no mundo e das contradições da época, que Hegel (1770-1831), refletindo sobre as possibilidades do conhecimento, logo na Introdução à Fenomenologia do Espírito, alerta-nos sobre o procedimento natural da filosofia que, antes de abordar o conhecimento efetivo do que é em verdade a 'coisa mesma', procura chegar a termos sobre o que significa conhecer e, ainda, a sua função em relação ao absoluto, isto é, de controle ou de seu acesso, o que implica uma crítica à filosofia transcendental de Kant (HEGEL: 1992).

A superação do kantismo parte do entendimento que o conhecimento se refere ao conhecer a coisa mesma, não a sua representação. Para Hegel (1992), a representação não nos revela o objeto em sua pureza, mas somente aquilo pelo qual o meio ou instrumento nos permitiu contemplar. Cabe à filosofia a tarefa de apreender a verdade, o absoluto, e não de averiguar que nada é possível conhecer, ou que não se pode compreender a verdade das coisas, somente uma verdade finita e passageira, ou seja, uma verdade que ao mesmo tempo não seja verdadeira.

A ideia fundamental da filosofia de Hegel (1992), caracterizado como idealista objetivo, é a identidade do ser e do pensamento. Isto quer dizer que o mundo real deve ser compreendido como uma manifestação do espírito, da ideia absoluta. Essa Ideia Absoluta se desenvolve passando por três fases. Na primeira, manifesta seu conteúdo, em categorias lógicas que 'se transformam umas às outras'. Em seguida, a ideia transforma-se em outro ser, 
que é a natureza que não é outra coisa senão 'o autodesenvovimento das categorias lógicas que constituem sua essência espiritual'. Na terceira fase, a Ideia Absoluta desenvolve-se no pensamento e na história, 'retornando a si mesma para conhecer seu conteúdo nas diferentes manifestações da consciência e da atividade humana'.

Hegel (1992) define o espírito como 'a essência absoluta e real que se sustém a si mesma'. O espírito objetivo 'é a Ideia Absoluta, mas só como ideia que é em si; e estando aquele, portanto, no terreno da finidade, sua racionalidade real conserva o aspecto da aparência exterior'. A Ideia Absoluta é pura forma do conceito, que institui seu conteúdo como sendo ela mesma.

Objetiva demonstrar que a fundamentação absoluta do saber resulta de uma história cujas sucessivas etapas da consciência se configuram em oposições dialeticamente conectadas de maneira que no fim, somente no fim, a verdade se estabeleça enquanto saber absoluto.

Esses teóricos tentaram responder questões como: todo o homem pode conhecer? (Descartes); como todo o homem pode conhecer? (Kant); como se dá a relação sujeito e objeto no conhecimento? (Hegel). Essas tendências vão sendo desenvolvidas ao longo dos séculos. O conhecimento continua sendo objeto de estudo e reflexão. Novos enfoques são apresentados na busca de superar concepções e pensamentos. O conhecimento permanece no centro das grandes questões: é possível conhecer o mundo? Pode o sujeito captar o mundo em toda a sua dimensão, não só o fenômeno, mas a ‘coisa em si'? É capaz o homem de desvendar as leis que regem o universo? Nossa consciência tem a capacidade de refletir a realidade objetiva?

\section{POSITIVISMO E MATERIALISMO DIALÉTICO}

O final do século XVIII e início do século XIX foram marcados pela eclosão de guerras simultâneas e subsequentes. A monarquia foi derrubada, a República estabelecida e uma nova era da história humana proclamada:

A grande camada de gelo dos sistemas agrários tradicionais e das relações sociais do campo cobria o fértil solo do crescimento econômico. Ela tinha que ser derretida a qualquer custo, de maneira que o solo pudesse ser arado pelas forças da empresa privada em busca de lucro. Isso implicava três tipos de mudanças: [....] a terra tinha que ser transformada em mercadoria, possuída por proprietários privados e livremente negociável por eles. [...] ela tinha que passar a ser propriedade de uma classe de homens desejosos de desenvolver seus recursos produtivos para o mercado e estimulados pela razão, isto é, pelos seus próprios interesses e pelo lucro, esses dois objetivos esclarecidos. [...] a grande massa da população rural tinha que ser transformada de alguma forma, pelos menos em parte, em trabalhadores assalariados, com liberdade de movimento, para o crescente setor não agrícola da economia. (HOBSBAWN: 2009, p. 210) 
Para Hobsbawn (2009), os passos legais efetivos para os sistemas burgueses de propriedade da terra foram dados assim na maior parte entre 1789 e 1812. Suas consequências, fora da França e de algumas áreas adjacentes, fizeram-se sentir muito mais vagarosamente, principalmente, devido à força da reação econômica e social após a derrota de Napoleão. Em geral, cada novo avanço do liberalismo fazia as revoluções legais darem mais um passo da teoria à prática, e cada recuperação dos velhos regimes retardavam-nas, principalmente nos países católicos, onde a secularização e a venda das terras da Igreja era uma das mais urgentes exigências dos liberais.

\begin{abstract}
As ferrovias e os navios a vapor mal tinham começado a criar um único mercado mundial agrícola quando da grande depressão agrária do final do século XIX. A agricultura local era, portanto, grandemente protegida da competição internacional ou até mesmo interprovincial. A competição industrial pouco efeito produzia sobre os inúmeros ofícios de aldeia ou manufaturas domésticas, exceto talvez o de direcionálos para a produção para mercados maiores. Os novos métodos agrícolas - fora das áreas de agricultura capitalista bem-sucedida - eram lentos para penetrar na aldeia, embora novas culturas industriais [...] e as novas culturas de alimentos [...] fizessem surpreendentes avanços. Era preciso uma extraordinária conjuntura econômica [...] para produzir um verdadeiro cataclismo em uma sociedade agrária por meios puramente econômicos. (HOBSBAWN: 2009, p. 230)
\end{abstract}

Foi nesse contexto, por volta de 1830, que Augusto Comte publica O Curso de Filosofia Positiva e Karl Marx e Engels (1848) publicaram o Manifesto do Partido Comunista. Essas duas vertentes clássicas do conhecimento estão vinculadas às origens de uma tradicional polarização entre idealismo e materialismo. O primeiro considera primário o espírito, o pensamento, a ideia, a consciência. O segundo, vê a matéria como primeira e a ideia e o pensamento como secundários.

Neste estudo, o nosso objetivo central é compreender, a partir de uma retomada histórica, os fundamentos epistemológicos que sustentam a teoria positivista (Augusto Comte) e o materialismo dialético (Karl Marx), em meio à emergência do pensamento moderno.

\title{
POSITIVISMO: ORIGEM E FUNDAMENTOS
}

O positivismo não surge no século XIX, com Augusto Comte. Suas raízes podem ser encontradas no empirismo, já na antiguidade. Mas as bases concretas e sistematizadas dele estão, seguramente, nos séculos XVI, XVII e XVIII, com Bacon, Descartes, Hobbes e Hume.

Emerge como uma reação à filosofia especulativa, especialmente a representada pelo idealismo clássico alemão (Kant e Hegel), que imperava no pensamento europeu da época de Comte. Essa filosofia se colocou no extremo oposto da especulação pura, exaltando, sobretudo, os fatos. 
O caráter fundamental da filosofia positivista, para o seu criador Augusto Comte, é tomar todos os fenômenos como sujeitos a leis naturais, cuja descoberta precisa e cuja redução ao menor número possível constituem o objetivo de todos os nossos esforços, considerando como absolutamente inacessível e vazia de sentido para nós a investigação das chamadas causas, sejam primeiras, sejam finais. (COMTE: 1998, p. 7).

Ao positivismo não interessava as causas dos fenômenos, porque isso não era positivo, não era tarefa da ciência. Buscar as causas dos fatos, sejam elas primeiras ou finais, era crer na capacidade de conhecer do ser humano, era ter uma visão desproporcionada da força intelectual do ser humano. Assim, tendo os fatos como único objeto da ciência, fatos que podiam ser observados, a atitude positiva consistia em descobrir as relações entre as coisas (COMTE: 1998).

O objeto central da filosofia positivista se reduz a estudar a marcha efetiva do espírito humano em exercício, graças ao exame dos processos realmente empregados para obter os diversos conhecimentos exatos que já adquiriu. (COMTE: 1998, p. 13). Comte reforça a ideia de que a sociedade só pode ser adequadamente reorganizada através de uma completa reforma intelectual do homem. Por essa razão, estruturou o seu pensamento em torno de três temas básicos. Em primeiro lugar, uma filosofia da história com o objetivo de mostrar as razões pelas quais uma certa maneira de pensar (chamada por ele filosofia positiva ou pensamento positivo) deve imperar entre os homens. Em segundo lugar, uma fundamentação e classificação das ciências baseadas na filosofia positiva. Finalmente, uma sociologia que, determinando a estrutura e os processos de modificação da sociedade, permitisse a reforma prática das instituições. A esse, deve-se acrescentar a forma religiosa assumida pelo plano de renovação social, proposto por Comte nos seus últimos anos de vida (COMTE: 1998).

O positivismo de Comte (1998) busca explicar a Lei dos três Estados, relacionando-a com a evolução histórica e cultural da humanidade. Essa Lei consiste em que cada ramo de nossos conhecimentos passa progressivamente por três Estados historicamente diferenciados: estado teológico ou fictício, estado metafísico ou abstrato e estado científico ou positivo. Esses três sistemas de concepções, para Comte (1998), sobre o conjunto de fenômenos, se excluem mutuamente: "a primeira é o ponto de partida necessário da inteligência humana; a terceira, seu estado fixo e definitivo; e a segunda, unicamente destinado a servir de transição".

No estado teológico (COMTE: 1998), os fenômenos são produzidos pela ação direta e contínua de agentes sobrenaturais, mais ou menos numerosos, cuja intervenção arbitrária explica todas as anomalias aparentes do universo; no estado metafísico, modificação geral do primeiro, os agentes sobrenaturais são substituídos por forças abstratas, verdadeiras entidades 
(abstrações personificadas) inerentes aos diversos seres do mundo, e concebidas como capazes de engendrar por elas próprias todos os fenômenos observados, cuja explicação consiste, então, em determinar para cada um uma entidade correspondente; e, no estado positivo, o espírito humano, reconhecendo a impossibilidade de obter noções absolutas, renuncia a procurar a origem e o destino do universo, a conhecer as suas causas íntimas, para descobrir, graças ao raciocínio e à observação, suas leis efetivas [...] suas relações invariáveis de sucessão e de similitude. A explicação dos fatos resume-se, de agora em diante, na ligação estabelecida entre os diversos fenômenos particulares e alguns fatos gerais (COMTE: 1998, p. $4)$.

O segundo tema básico da obra de Comte (1998) refere-se à classificação das ciências, que aborda a hierarquização das ciências, partindo do Estado dos fenômenos mais simples e gerais em direção aos mais complexos e específicos, definindo a seguinte ordem: matemática, astronomia, física, química, biologia e sociologia. Sem o estudo hierárquico dessa educação científica, o ser humano não atingiria o Estado maduro da racionalidade positiva. Caso o conhecimento não seguisse essa lógica e suscetibilidade, corria o risco de se produzir uma perda irreparável na formação racional do ser humano.

O terceiro tema básico da sua obra tem como centralidade a reforma da sociedade que seguiria a reorganização intelectual, a moral e, finalmente, a política. Entre outras abordagens, a terceira parte da obra de Comte destaca que uma das tarefas da filosofia positiva seria restabelecer a ordem na sociedade capitalista industrial, que havia sido quebrada pela Revolução Francesa. Comte (1998) defende a legitimidade da exploração industrial, concorda com a estratificação da sociedade em classes sociais, inclusive a existência de capitalistas e proletários.

Uma das afirmações básicas do positivismo está representada pela sua ideia da unidade metodológica para investigação dos dados naturais e sociais. Partia-se da ideia de que tantos os fenômenos da natureza, como os da sociedade estavam regidos por leis invariáveis.

Só a filosofia positiva pode ser considerada a única base solida da reorganização social, que deve terminar o estado de crise no qual se encontram, há tanto tempo, as nações mais civilizadas. (COMTE: 1998, p. 17).

Segundo Comte (1998), a experiência nunca mostra mais do que uma limitada interconexão entre determinados fenômenos. Cada ciência ocupa-se apenas com certo grupo de fenômenos, irredutíveis uns aos outros. A unidade que o conhecimento pode alcançar seria, assim, inteiramente subjetiva, radicando no fato de empregar-se um mesmo método, seja qual 
for o campo em questão: uma idêntica metodologia produz convergência e homogeneidade de teorias.

Essa unidade do conhecimento não é apenas individual, mas também coletiva. Isso faz da filosofia positiva o fundamento intelectual da fraternidade entre os homens, possibilitando a vida prática em comum. A união entre a teoria e a prática seria muito mais íntima no estado positivo do que nos anteriores, pois o conhecimento das relações constantes entre os fenômenos torna possível determinar seu futuro desenvolvimento. $\mathrm{O}$ conhecimento positivo caracteriza-se pela previsibilidade: "ver para prever" é o lema da ciência positiva. A previsibilidade científica permite o desenvolvimento da técnica e, assim, o estado positivo corresponde à indústria, no sentido de exploração da natureza pelo homem.

O espírito positivo instaura as ciências como investigação do real, do certo e indubitável, do precisamente determinado e do útil. Nos domínios do social e do político, o estágio positivo do espírito humano marcaria a passagem do poder espiritual para as mãos dos sábios e cientistas e do poder material para o controle dos industriais.

Principais características do positivismo: considera a realidade constituída por partes isoladas; não aceita outra realidade que não sejam os fatos, fatos que possam ser observados; não interessavam as causas dos fenômenos, mas as relações entre as coisas; não há interesse em conhecer as consequências dos achados, o que fortaleceu a ideia de 'neutralidade das ciências'; rejeição ao conhecimento metafísico, à metafísica; considera verdadeiro aquilo que empiricamente é verdadeiro (formulou o princípio da verificação); ideia de unidade metodológica para investigação dos dados naturais e sociais; utilização do emprego da 'variável' no processo de quantificação dos fatos sociais (as técnicas de amostragem, os tratamentos estatísticos e os estudos experimentais severamente controlados foram instrumentos usados para concretizar estes propósitos); busca de uma linguagem única, comum para todas as ciências (fisicalismo); se o que reconhecemos como conhecimento é aquilo que pode ser testado empiricamente, não há possibilidade de conhecimento elaborado 'a priori' (crítica à tese Kantiana); distinção entre valor e fato, sendo o primeiro entendido como objetos da ciência, e o segundo como expressões culturais, ficaram de fora da análise positivista; reconheciam apenas dois tipos de conhecimento científico: o empírico e o lógico (COMTE: 1998).

\section{MATERIALISMO DIALÉTICO: ORIGEM E FUNDAMENTOS}


$\mathrm{Na}$ tentativa de superar criticamente pensamentos e filosofias, sobretudo as bases epistemológicas de Hegel e Feuerbach, Marx (1818-1883) defende o materialismo dialético, tendo como referência Demócrito e Epicuro (sobre o materialismo) e Heráclito (sobre a dialética, do grego $=$ dois logos, duas opiniões divergentes). Nessa perspectiva, revoluciona o pensamento filosófico, invertendo toda a lógica do pensamento, até então elaborado, sobretudo, da corrente positivista.

A dialética hegeliana (1992) era a dialética do idealismo (o mundo real deve ser compreendido como manifestação do espírito, da ideia absoluta. Espírito entendido como a essência absoluta e real que se sustenta em si mesma. E ideia absoluta, como princípio ativo que se expressa em seu autoconhecimento), e a dialética do marxismo (1998) é a dialética do materialismo, em que a matéria é o princípio primeiro e o espírito, a ideia, o aspecto secundário (suas concepções mudam de acordo com a evolução do pensamento científico). Sustenta-se nas conclusões da ciência para explicar o mundo, o homem e a vida. Nega a existência da alma, de outra vida e de Deus. A consciência, que é produto da matéria, permite que o mundo se reflita nela, o que assegura a possibilidade que tem o homem de conhecer o universo. A ideia materialista do mundo reconhece que a realidade existe independentemente da consciência: "Não é a consciência que determina a vida, mas sim a vida que determina a consciência. [...] é na vida real que começa, portanto, a ciência real, positiva, a análise da atividade prática, do processo, do desenvolvimento prático dos homens.” (MARX: 1998, p. 20).

Ao contrário da filosofia alemã, que desce do céu para a terra, aqui é da terra que se sobe para o céu. [...] não partimos do que os homens dizem, imaginam e representam, tampouco do que eles são nas palavras, no pensamento, na imaginação e na representação dos outros, para depois se chegar ao homens de carne e osso; mas partimos dos homens em sua atividade real, é a partir de seu processo de vida real que represemos também o desenvolvimento dos reflexos e das repercussões ideológicas desse processo vital. (MARX: 1998, p. 19). ${ }^{2}$

Tanto a dialética hegeliana quanto a dialética marxista defendem que as leis do pensamento são as leis da realidade, ou seja, a realidade é contraditória, mas a contradição supera-se na síntese. Hegel considerava ontologicamente a contradição (antítese) e a superação (síntese); Marx (1998) considerava historicamente como contradição de classes vinculada a certo tipo de organização social. Hegel (1992) apresenta uma filosofia que procura demonstrar a perfeição do que existe (divinização da estrutura vigente); Marx apresenta uma filosofia revolucionária que procura demonstrar as contradições internas da sociedade de classes e as exigências de superação, ou seja, o desvelamento e os mecanismos de ocultamento da estrutura vigente. (MARX: 1998, p. 7-54). 
Feuerbach (1804-1872), em seu apoio ao materialismo, atacou as ideias de Hegel, especialmente, aquelas que identificavam a essência humana com a autoconsciência. Em a Essência do Cristianismo, Feuerbach inverteu o significado do que Hegel chamava de alienação, do processo pelo qual a Ideia Absoluta se fazia Ser-Outro na natureza e se realizava dialeticamente nas obras do espírito. Da crítica à dialética idealista, partiu Feuerbach à crítica da religião e da essência do cristianismo. Pretendia trazer a religião do céu para a Terra. Ao invés de haver Deus criado o homem à sua imagem e semelhança, foi o homem quem criou Deus à sua imagem. Libertar-se desta ilusão seria necessário a fim de recuperar a essência humana alienada e restabelecer a comunidade verdadeira do gênero humano. Seu objetivo era conservar intactos os valores morais em uma religião da humanidade, na qual o homem seria Deus para o homem. O homem é o Deus do homem. No reconhecimento desta verdade estava a grande virada libertadora da história (MARX: 1998, p. 5-54).

Marx e Engels (1998) se apropriam das obras e do pensamento de Feuerbach em sua ideia materialista da realidade: humanismo materialista. Mas, Marx e Engels, em suas célebres Teses sobre Feuerbach, em 1845, rebatem sua concepção filosófica geral e conservam a dimensão ética recebida de Kant e, sobretudo, a dialética de Hegel, ao mesmo tempo em que traçam as bases principais de uma profunda revolução filosófica que envolve a integração do princípio da dialética no corpo do materialismo e a reconstrução deste como materialismo dialético.

Para Marx (1998), o humanismo e a dialética de Feuerbach eram estáticos, ou seja, o homem não tem dimensões, está fora da sociedade e da história, é pura abstração. Marx considera indispensável compreender a realidade histórica em suas contradições, para tentar superá-las dialeticamente.

O materialismo dialético é a base filosófica do marxismo e, como tal, realiza a tentativa de buscar explicações coerentes, lógicas e racionais para os fenômenos da natureza, da sociedade e do pensamento.

Para Marx (1998), as relações sociais são inteiramente interligadas às forças produtivas, ou seja, adquirindo novas forças produtivas, os homens modificam o seu modo de produção e modificam todas as relações sociais. O modo pelo qual a produção material de uma sociedade é realizada constitui o fator determinante da organização política e das representações intelectuais de uma época.

Ao produzirem seus meios de existência, os homens produzem indiretamente sua própria vida material. A maneira como os homens produzem seus meios de existência depende, antes de mais nada, da natureza dos meios de existência já encontrados e que 
eles precisam reproduzir. Não se deve considerar esse modo de produção sob esse único ponto de vista, ou seja, enquanto reprodução da existência física dos indivíduos. Ao contrário, ele representa, já, um modo determinado da atividade desses indivíduos, uma maneira determinada de manifestar sua vida, um modo de vida determinado. A maneira como os indivíduos manifestam sua vida reflete exatamente o que eles são. $\mathrm{O}$ que eles são coincide, pois, com sua produção, isto é, tanto com o que eles produzem quanto com a maneira como produzem. O que os indivíduos são depende, portanto, das condições materiais da sua produção. (MARX: 1998, p. 11).

Para Marx, essa produção só aparece com o aumento da população, pois essa pressupõe o intercâmbio dos indivíduos entre si. A forma desses intercâmbios se acha, por sua vez, condicionada pela produção.

E é a partir do momento em que se opera a divisão entre o trabalho material e o trabalho intelectual, com o aumento das trocas e dos intercâmbios, que surge a divisão do trabalho, que implica, para Marx, todas essas contradições e repousa por sua vez na divisão natural do trabalho na família e na separação da sociedade em famílias isoladas e opostas umas às outras: "[...] essa divisão desigual do trabalho encerra, ao mesmo tempo, a repartição do trabalho e de seus produtos, distribuição desigual, na verdade, tanto em quantidade quanto em qualidade". (MARX: 1998, p. 27).

Para Marx, a divisão do trabalho implica também a contradição entre o interesse do indivíduo isolado e o interesse coletivo de todos os indivíduos que mantêm relações entre si:

É justamente essa contradição entre o interesse particular e o interesse coletivo que leva o interesse coletivo a tomar, na qualidade do Estado, uma forma independente, separada dos interesses reais do indivíduo e do conjunto e a fazer ao mesmo tempo às vezes de comunidade ilusória, mas sempre tendo por base concreta os laços existentes em cada agrupamento familiar e tribal, tais como laços de sangue, de língua, divisão do trabalho em uma larga escala, e outros interesses; e entre esses interesses encontramos, mais adiante, os interesses de classes já condicionadas pela divisão do trabalho, que se diferenciam em todo agrupamento desse gênero e no qual uma domina todas as outras. (MARX: 1998, p. 29).

As transformações da sociedade, no materialismo dialético, ocorrem pela oposição de contrários - tese e antítese - que têm como resultado uma unidade transformadora, a síntese. A luta de classes, na análise marxista, é o agente transformador da sociedade. O antagonismo entre dominados e dominantes induz às lutas e às transformações sociais. Esse antagonismo está relacionado à estrutura produtiva, especialmente à existência da propriedade privada.

O materialismo dialético reconhece que a origem do seu desenvolvimento está em seu interior, nos elementos contrários que, no processo de transformação, se constituem opostos. Vale ressaltar que esses opostos não existem um sem o outro e estão em interação constante (= contradição = luta de contrários $)$. A contradição é fonte central do movimento, da transformação dos fenômenos. A possibilidade de que os contrários não existem sem o outro, 
constitui a unidade dos contrários. No entanto, tanto na unidade quanto na luta existe movimento. Ambos se interpenetram devido à semelhança de sua essência (= identidade), quando se resolve a contradição, ou seja, quando se realiza a transição dos contrários de um para o outro. É importante destacar que a identidade é também diferença, podendo estar nessa compreensão a origem da contradição dialética (MARX: 1998).

Pode-se dizer que a concepção materialista apresenta três características: materialidade do mundo, isto é, todos os fenômenos, objetos e processos que se realizam na realidade são materiais (são aspectos diferentes da matéria em movimento); a matéria é anterior à realidade, ou seja, isso significa reconhecer que a consciência é um reflexo da matéria (essa existe objetivamente e se constitui numa realidade objetiva); e, por último, o mundo é conhecível, isto é, tem o homem a capacidade de conhecer a realidade gradualmente, por meio do desvelamento da realidade apresentada.

\section{REFERÊNCIAS BIBLIOGRÁFICAS}

COMTE, Auguste. Curso de Filosofia Positiva; discurso preliminar sobre o conjunto do positivismo; catecismo positivista / Augusto Comte. Tradução: José Arthur Giannotti e Miguel Lemos. - São Paulo: Nova Cultural, 1988. (Os pensadores)

DESCARTES, René. Discurso do Método. In Os Pensadores. São Paulo. Nova Cultura, 1999. KANT, Immanuel. Crítica da Razão Pura. São Paulo. Editora Martin Claret, 2002.

HEGEL, G.W.F. Fenomenologia do Espírito. Petrópolis-RJ. Vozes. 1992.

HOBSBAWN, Eric. A Era das Revoluções (1789 - 1848). Rio de Janeiro, Paz e Terra, 2009. MARK, Karl. A Ideologia Alemã. / Karl Marx e Friedrich Engels; [Introdução de Jacob Gorender]: tradução Luís Cláudio de Castro e Costa - São Paulo: Marins Fontes, 1998. - (Clássicos).

\footnotetext{
${ }^{1}$ Para Kant (2002, p.58) a razão é a faculdade que nos fornece os princípios do conhecimento a priori. Portanto, a razão pura é a que contém os princípios para conhecer algo absolutamente a priori.
} 